NIST Technical Note 1868

\title{
Characterizing Indoor Air Quality Performance Using a Graphical Approach
}

\author{
Kevin Teichman \\ Cynthia Howard-Reed \\ Andrew Persily \\ Steve Emmerich
}




\title{
NIST Technical Note 1868
}

\section{Characterizing Indoor Air Quality Performance Using a Graphical Approach}

\author{
Kevin Teichman \\ Office of Research and Development \\ U.S. Environmental Protection Agency \\ Washington, DC \\ Cynthia Howard-Reed \\ Andrew Persily \\ Steve Emmerich \\ Energy and Environment Division \\ Engineering Laboratory
}

This publication is available free of charge from: http://dx.doi.org/10.6028/NIST.TN.1868

March 2016

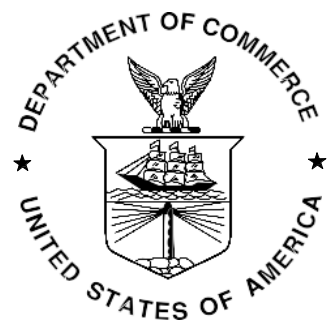

U.S. Department of Commerce Penny Pritzker, Secretary 
Certain commercial entities, equipment, or materials may be identified in this document in order to describe an experimental procedure or concept adequately. Such identification is not intended to imply recommendation or endorsement by the National Institute of Standards and Technology, nor is it intended to imply that the entities, materials, or equipment are necessarily the best available for the purpose.

National Institute of Standards and Technology Technical Note 1868 Natl. Inst. Stand. Technol. Technical Note 1868, 25 pages (March 2016)

CODEN: NTNOEF

This publication is available free of charge from http://dx.doi.org/10.6028/NIST.TN.1868 


\section{ABSTRACT}

In this paper, we describe and demonstrate a graphical approach that can be used to illustrate the performance of buildings with respect to indoor air quality (IAQ). We start by describing previous efforts to establish IAQ and indoor environmental quality (IEQ) metrics, and then, in the absence of an adequate or agreed-upon IAQ metric(s), describe a graphical approach to presenting IAQ performance. This approach displays measured or predicted levels of indoor pollutants relative to health-based guidelines or other appropriate reference values. The development of this graphical approach leads to several challenging questions regarding how to characterize building IAQ performance, including the determination of relevant contaminant concentration limits and the impacts of contaminant mixtures. This paper discusses those questions with the intent of promoting future dialog on how to characterize IAQ performance using this graphical or any other approach. Lastly, we briefly describe how the approach can be extended to illustrate the performance of buildings with respect to IAQ and other building parameters (e.g., energy and water consumption).

Keywords: building performance; contaminants; indoor air quality; indoor environmental quality; high-performing buildings; metrics.

\section{INTRODUCTION}

Defining a "high-performing building" is challenging given the multiple performance goals that need to be considered, as well as the lack of accepted performance criteria for many of them. These goals include indoor environmental quality, energy consumption, water use, waste generation, resource conservation, and transportation impacts. Characterizing indoor environmental quality, specifically indoor air quality (IAQ), in buildings is especially difficult 
due to the currently incomplete understanding of the impacts of indoor pollutant exposures on human health. Nonetheless, the building community is being challenged to reduce the environmental impacts of buildings, while maintaining, if not improving, indoor environments that are conducive to occupant health, comfort, and productivity.

The overarching goal of reducing the environmental impacts of buildings is addressed in discussions of green or sustainable buildings, and a number of programs, standards, codes, and other efforts are in place to promote, and in some cases require, the design and construction of buildings with these attributes [1-4]. These efforts speak to the need for "high performance," which, in addition to energy, generally includes a range of non-energy performance attributes such as IAQ, water consumption, the use of recycled and regionally-manufactured materials, and the diversion of construction waste from landfills. Many discussions of high-performance and sustainable buildings are focused more on energy performance than these other attributes, which is a limitation that needs to be overcome as these efforts advance [5].

In this paper, we describe and demonstrate a graphical approach that can be used to illustrate the IAQ performance of buildings. We start by describing previous efforts to establish IAQ and indoor environmental quality (IEQ) metrics, and then, in the absence of an adequate or agreedupon IAQ metric(s), describe a graphical approach to presenting IAQ performance. This approach displays measured or predicted levels of indoor pollutants relative to health-based guidelines or other appropriate reference values. The development of this graphical approach leads to several challenging questions regarding how to characterize building IAQ performance, including the determination of relevant contaminant concentration limits and the impacts of contaminant mixtures. This paper discusses those questions with the intent of promoting future 
dialog on how to characterize IAQ performance using this graphical or any other approach. This approach, once developed further and accepted by the building community, is intended to enable building designers, owners, operators, and occupants to more easily understand the performance of a building with respect to IAQ.

\section{THE NEED FOR AN IAQ METRIC}

Part of the reason that IAQ is not always emphasized in descriptions of buildings is the difficulty in quantifying IAQ performance due to the lack of accepted metrics. Challenges to quantifying IAQ performance using a single, accepted metric(s) include the large number of airborne contaminants of interest, a lack of accepted guideline values for the health impacts of many of these contaminants, and the need to also consider occupant comfort. The lack of IAQ metrics has been identified as a key gap in the IAQ field in many previous discussions $[6,7]$.

Metrics for energy use, e.g., energy use intensity (EUI) expressed as energy consumption either per unit floor area or per person, have become commonly accepted to enable building energy performance to be expressed and compared [8]. However, while proposals for IAQ metrics have been put forward, no such widely accepted metric(s) currently exist.. Nevertheless, IAQ metrics are needed for evaluating and comparing indoor environments and for facilitating and quantifying IAQ improvements.

\section{Previously Proposed IAQ Metrics}

Several IAQ metrics addressing contaminant concentrations have been proposed. These metrics range from concentrations of single contaminants to indices that incorporate the concentrations of multiple pollutants. An example of an existing single contaminant metric is the EPA action 
level for radon [9]. EPA has recommended that homeowners test for elevated levels of radon in their homes. If a home's radon concentration is above $0.148 \mathrm{~Bq} / \mathrm{L}(4 \mathrm{pCi} / \mathrm{L}), \mathrm{EPA}$ recommends implementing a mitigation strategy to lower the radon level. This guideline has been very useful, because it provides homeowners, installers of radon control technologies, and local authorities with a target concentration and associated actions.

Another example of a single contaminant metric is the indoor concentration of carbon dioxide $\left(\mathrm{CO}_{2}\right)$. This particular example, however, highlights some of the challenges in setting a contaminant benchmark concentration. Indoor $\mathrm{CO}_{2}$ levels have been of interest for many years due to their relationship with ventilation rates relative to occupancy levels and the availability of affordable measurement instruments. However, indoor $\mathrm{CO}_{2}$ levels are generally do not directly impact health and comfort, except in confined spaces that are not relevant to building performance discussions. Recent research by Satish et al. [10] suggests indoor $\mathrm{CO}_{2}$ levels may directly impact occupant decision making, meriting more research on this topic. Nevertheless, while indoor $\mathrm{CO}_{2}$ levels may not be a good indicator of overall IAQ, they can provide a useful indication of the acceptability of a space in terms of human body odor, some aspects of perceived IAQ, and per person outdoor air ventilation rates. However, indoor $\mathrm{CO}_{2}$ levels relative to a concentration of $1800 \mathrm{mg} / \mathrm{m}^{3}$ (equivalent to $1000 \mathrm{ppm}_{\mathrm{v}}$ ) have been mistakenly viewed as indicative of good or bad IAQ, despite well-established limitations in the interpretation of this or any other particular reference value [11].

A step beyond metrics based on a single airborne contaminant is to combine the concentrations of multiple contaminants. For example, Mølhave [12] discusses measuring the total concentration of non-reactive volatile organic compounds (TVOC) and comparing this total to an 
irritation and discomfort scale, where $<0.20 \mathrm{mg} / \mathrm{m}^{3}$ was identified as having "no effect" and $>3 \mathrm{mg} / \mathrm{m}^{3}$ as "expected discomfort." Since the early proposals of such applications of TVOC levels, several questions have been raised regarding the appropriateness of TVOC as an IAQ indicator [13]. Part of the problem is that different researchers employ different methodologies for measuring TVOC, making it difficult to compare results across studies. Second, summing all of the measured volatile organic compounds (VOC) in effect assumes that the toxicities and irritancies of the individual compounds are similar and the resulting health and comfort effects are additive. Lastly, VOC can react with each other and with other chemicals to sometimes form chemicals of greater concern [14]. Therefore, Mølhave and Nielsen [15] concluded that a TVOC metric may be best used as a screening tool to identify indoor environments with high levels of non-reactive VOC that cause "nonspecific sensory irritation." Table B-2 of ASHRAE Standard 62.1 contains a recommendation against setting target values of TVOC, noting a preference instead for targeting individual VOC [16]. The ASHRAE IAQ Guide contains additional information questioning the use of TVOC as an IAQ metric [17].

Tenbrinke et al. [18] expanded the concept of a TVOC metric to six additional metrics incorporating multiple VOC. The proposed metrics included the sum of VOC measured with a gas chromatograph (GC) flame ionization detector or a GC and mass spectrometer, the sum of VOC individually weighted by their relative irritancy or relative odor threshold, the sum of VOC according to their chemical class, and two additional metrics defined by principal component analysis (air freshener/cleaning product emissions and relative irritancy of VOC). Ten Brinke et al. evaluated these metrics using data from the California Healthy Buildings Study, which included 12 office buildings in Northern California and measured concentrations of 39 VOC. Based on a multivariate logistic regression analysis, relationships between occupant symptoms 
and VOC metrics were determined. Of the seven exposure metrics tested, the two based on principal component analysis were the only ones to be statistically significant in terms of symptom prediction.

A number of other IAQ metrics based on multiple pollutants have also been proposed. For example, Sekhar, Tham [19] developed an "indoor pollutant standard index," which is based on eight IAQ parameters including $\mathrm{CO}_{2}$, carbon monoxide $(\mathrm{CO})$, formaldehyde (HCHO), TVOC, particulate matter (PM), bacteria, fungi, and thermal comfort. [20] proposed a "total tolerance index" that summed the ratio of measured contaminant concentrations to the maximum allowable concentration for the individual gaseous contaminants of concern. This index was tested using 41 “non-problem” buildings from the EPA's Building Assessment Survey and Evaluation (BASE) study [21]. Based on an average of contaminant concentrations measured in the 41 buildings, the total tolerance index was 0.88 , which was consistent with the occupants' perceptions in those buildings.

Moschandreas and Sofuoglu [22] proposed an indoor air pollution index that combines a range of IAQ contaminants. This index uses a four-tier, tree-structured calculation that yields a single indicator of IAQ. The first level includes contaminants (HCHO, TVOC, CO, nitrogen dioxide $\left(\mathrm{NO}_{2}\right)$, total suspended particulate (TSP), respirable suspended particulate (RSP), fungi, and bacteria), and the fourth level is a "global" metric that ranges from 0 (lowest pollution level) to 10 (highest pollution level). The authors further demonstrate the use of this index to choose the most appropriate control strategies based on identification of the primary cause of poor IAQ and an analysis of cost. 
Recently, Mouradian and Boulanger [23] proposed an IAQ metric based on four groups of pollutants representative of similar behavior, use, or effect. The four groupings are: $\mathrm{CO}_{2}$ as a marker linked to human occupancy; $\mathrm{NO}_{2}$ and sulfur dioxide $\left(\mathrm{SO}_{2}\right)$ in dwellings and ozone $\left(\mathrm{O}_{3}\right)$ in offices linked to occupant activities; CO and seven VOC linked to materials, activities, and behavior; and particles with diameters both $2.5 \mathrm{um}$ and smaller $\left(\mathrm{PM}_{2.5}\right)$ and $10 \mathrm{um}$ and smaller $\left(\mathrm{PM}_{10}\right)$ linked to activities. Simulation results for these four groupings were graphed along with humidity and energy consumption for different building design alternatives. The authors concluded that currently available ventilation systems and required airflow rates are well suited for low energy buildings and can provide suitable IAQ as long as the systems are correctly designed and installed.

While not an IAQ metric, ANSI/ASHRAE Standard 62.1-2013 Ventilation for Acceptable Indoor Air Quality contains a collection of reference values derived from other sources in an informative (i.e., not required for compliance with the standard) appendix [16]. While these values are not provided as a means of compliance, they are included with a useful discussion of the challenges in developing and applying such reference values.

\section{A New Approach to IAQ Metrics}

As noted above, although there has been some useful work to establish contaminant-based metrics, a single IAQ metric is not likely to be accepted and standardized in the near future for multiple reasons. Foremost among these is the incomplete understanding of both acute and chronic human health effects data on exposures to low-level concentrations of contaminants and the effects resulting from exposures to contaminants in combination. Data are also incomplete on how contaminant concentrations impact occupant comfort, perceived IAQ, the prevalence of sick building syndrome symptoms, and productivity. The incomplete data on human response to 
contaminant concentrations in turn leads to a lack of concentration guidelines or other reference values for many contaminants, making it difficult to know which contaminants to measure and include in an IAQ metric. In addition, pollutant measurements are also often limited to concentrations that are above the minimum detection levels of less expensive, and thus more common, instruments. Limited standardization of monitoring equipment and measurement protocols also makes the repeatability of these measurements challenging. Given the noted challenges with a single IAQ metric and the associated need to quantify IAQ performance based on multiple parameters, the challenge remains of presenting a multi-dimensional metric in an understandable and meaningful fashion.

\section{A GRAPHICAL APPROACH TO IAQ METRICS}

This section describes and demonstrates a graphical approach to represent IAQ performance in buildings. The approach draws upon recent research in computational toxicology, which utilizes a similar graphical approach to represent the "toxicity footprint" of a chemical based on in vitro assays, chemical properties, and cellular pathways [24]. The approach described below provides the "IAQ performance footprint" of a building based on the concentrations of multiple contaminants.

Rather than trying to consolidate the many different dimensions of IAQ into a single metric, we propose to compare multiple IAQ-related parameters. In this paper, we have arbitrarily limited the discussion to twelve parameters, each of which is represented as an equal angular sector of a 
circle. More or less than twelve parameters could easily be included, and the angular width of the sectors could be varied to differentiate the relative significance of the parameters. The length of each sector represents the magnitude of the given parameter, e.g., the concentration of an indoor pollutant, and the circumference of the circle represents the upper limit for the parameter, e.g., an acceptable health benchmark or other appropriate reference value. If the parameter does not exceed its reference value, the length of the sector is proportionately shorter than the sector defined by the parameter's reference value. If the parameter exceeds its reference value, the length of the sector is proportionately longer than the sector defined by the parameter's reference value.

Where a given pollutant has no health benchmark or reference value, an empty sector is displayed. To distinguish this situation from one in which the measured or modeled concentration is significantly lower than the reference value, we have chosen to graph the latter circumstance with a sector that is one quarter of the length of the reference value, thereby signifying the measured concentration is well below the reference value. Similarly, when a concentration significantly exceeds its corresponding reference value, we have chosen to represent this concentration as 1.5 times the length of the reference value, signifying that the measured concentration is well above the reference value. These choices can certainly be revisited and other approaches employed for displaying low and high concentrations.

We recognize that in many cases it is very difficult to choose the health benchmark or reference value to be used for comparison to a measured pollutant concentration. For some pollutants, there are multiple such values from multiple sources; for others, there may be no such value from any source. Ideally, the health benchmark or reference value selected will correspond to the 
population to be protected (e.g., adults, children, seniors, asthmatics) from an adverse health effect (acute, chronic; cancer, non-cancer; reversible, irreversible) that could potentially result from exposure over the relevant period of time (e.g., 8 hours for typical office exposure scenarios). Nevertheless, selecting the benchmark or reference value is a key challenge with this approach as it reflects the lack of accepted values to characterize IAQ performance. Additional complexities arise due to the effects on human response associated with the interactions among different indoor environmental parameters, e.g., contaminant concentrations, temperature, and lighting. ASHRAE Guideline 10, Interactions Affecting the Achievement of Acceptable Indoor Environments, contains useful discussions of these issues [25].

One way to address measurement issues is to base an IAQ metric upon predicted contaminant concentrations using IAQ simulation models. Modeling has the additional advantage of enabling comparisons of the impact of alternative building designs and retrofits on IAQ. However, modeling is limited by the adequacy of the model used and its inputs, which themselves can be subject to significant uncertainty and variability. While the consistency of predicted concentrations among different models can be an issue, this has been improved with the development of standardized building scenarios [8], including scenarios specifically intended for IAQ analysis [26].

To illustrate the graphical approach, let us assume that we have either measured or modeled data on radon, PM2.5, and $\mathrm{CO}$ levels in a building over the course of a year. For radon, let us assume a measured annual average value of $0.111 \mathrm{~Bq} / \mathrm{L}(3 \mathrm{pCi} / \mathrm{L})$; for PM2.5, an annual average of $15 \mu \mathrm{g} / \mathrm{m}^{3}$ and a maximum 8 -h average concentration of $30 \mu \mathrm{g} / \mathrm{m}^{3}$; and for $\mathrm{CO}$, a maximum 8 -h average concentration of $8 \mathrm{mg} / \mathrm{m}^{3}$ and a maximum one-hour average concentration of $50 \mathrm{mg} / \mathrm{m}^{3}$. 
The next step is to identify relevant health benchmarks or reference values for these pollutants. For radon, EPA has established an action level of $0.148 \mathrm{~Bq} / \mathrm{L}$ (4 pCi/L) [9]. For PM2.5, the EPA national ambient air quality standard (NAAQS) is an annual average of $12 \mu \mathrm{g} / \mathrm{m}^{3}$ and a $24-\mathrm{h}$ average of $35 \mu \mathrm{g} / \mathrm{m}^{3}$ [27]. Lastly for CO, the NAAQS is $10 \mathrm{mg} / \mathrm{m}^{3}$ averaged over an 8 -h period and $40 \mathrm{mg} / \mathrm{m}^{3}$ averaged over a 1-h period [27]. Since one of the measurements is for a time period different than the available health benchmark, for illustrative purposes only, we assume that the time period of our measured concentration matches the time period of the health benchmark. Specifically, we compare the measured 8-h maximum PM2.5 concentration of 30 $\mu \mathrm{g} / \mathrm{m}^{3}$ to the $24-\mathrm{h}$ NAAQS of $35 \mu \mathrm{g} / \mathrm{m}^{3}$. These results are displayed in Figure 1.

In this example, the maximum concentration level of $\mathrm{PM}_{2.5}$ integrated over eight hours is below the selected reference value, which may not a concern, but the annual average $\mathrm{PM}_{2.5}$ concentration is above the reference value and therefore of more interest. Similarly, while the maximum concentration level of $\mathrm{CO}$ integrated over eight hours is low, there would perhaps be more concern about the peak one-hour concentration.

The proposed approach to displaying IAQ performance data has the following advantages. First, rather than questionably and perhaps subjectively combining IAQ parameters into a single metric, it preserves the robustness of the data and its ability to inform decision making relative to multiple desired health benchmarks or other reference values. Second, it enables users to select the IAQ pollutants that are most relevant to them. Lastly, as opposed to a histogram showing concentrations of individual pollutants, the approach provides a single graph illustrating the "IAQ performance footprint" of a building based on multiple contaminant concentrations. This graphical footprint" of IAQ performance enables both comparisons among multiple buildings 
and the comparison of proposed design alternatives and subsequent mitigation interventions in a single building. While the approach offers many advantages, it is important to reiterate that it relies on the judicious choice of contaminant concentrations to be measured or modeled and the availability of accepted health benchmarks or reference values for these contaminants to enable comparison.

\section{Applying the Approach to Existing Data}

To demonstrate this approach, we have graphed the results from two existing datasets: (1) the Small and Medium Sized Commercial Buildings (SMCB) field study [28], and (2) a simulation study of residential IAQ control interventions [29].

The data plotted in Figure 2 are from the SMCB study, with each value in the figure being the the $95^{\text {th }}$ percentile values reported in the study, with the exception of PM2.5 which was reported at the $75^{\text {th }}$ percentile. These data are also shown in Table 1 . The reference values used in the figure are as follows: (a) $1800 \mathrm{mg} / \mathrm{m}^{3}$ for $\mathrm{CO}_{2}$ despite the fact that $\mathrm{CO}_{2}$ is not a comprehensive indicator of IAQ and there are many problems with its measurement and interpretation [11]; (b) the PM2.5 NAAQS [27], and (c) individual VOC chronic reference exposure levels [30]. Note that the OEHHA reference exposure value for $\mathrm{HCHO}$ is for 8-h, since there is no chronic value. Figure 3 shows that for the buildings in the SMCB study, most of the $95^{\text {th }}$ percentile VOC concentrations were below their respective OEHHA reference exposure value; however, the $95^{\text {th }}$ percentile of $\mathrm{HCHO}$ exceeded its reference exposure value. 
Figure 3 uses the modeled data from Emmerich et al. [29] to show the impact of different interventions to address summertime concentrations of $\mathrm{CO}$ and $\mathrm{NO}_{2}$ in a kitchen in Boston with a maladjusted gas stove. The resultant concentrations show the impact of each intervention in isolation, i.e., one intervention is considered at a time with all other parameters held constant in the different simulations. These data are also shown in Table 2. The health benchmarks shown in the figure are the EPA one-hour NAAQS for CO, $43.2 \mathrm{mg} / \mathrm{m}^{3}$, and the EPA annual NAAQS for $\mathrm{NO}_{2}, 0.107 \mathrm{mg} / \mathrm{m}^{3}$ [27]. This figure shows that not only does proper adjustment of the stove have the greatest impact on lowering both $\mathrm{CO}$ and $\mathrm{NO}_{2}$ concentrations, it is the only intervention that reduces the $\mathrm{NO}_{2}$ concentration below the EPA NAAQS.

\section{DISCUSSION}

The effort to develop this graphical approach highlighted many challenges, including identifying the most important contaminants to include, selecting the concentration reference values to use for comparison, and accounting for the impacts of contaminant mixtures. All of these issues need to be addressed if this approach is going to be accepted and useful.

How do we know which are the most important pollutants needed to characterize IAQ performance? Should we select the pollutants that are: (a) the most toxic (e.g., those with carcinogenic or irreversible non-carcinogenic health endpoints), (b) those anticipated to lead to the greatest exposures, or (c) representative of different indoor pollutant classes (e.g., pollutants of outdoor origin, VOC from building materials, indoor products of combustion). Do all of these pollutants have at least one accepted health benchmark or reference value that is comparable to the anticipated indoor exposure period, and, if so, are our pollutant measurements being accurately made over these periods? 
To illustrate, in Figure 2, we plotted twelve pollutant concentrations drawn from the SMCB study (Bennett et al., 2011). While we arbitrarily chose twelve concentrations so that the sectors graphed would be easily distinguished, we intentionally chose twelve pollutants for which relevant reference values existed for anticipated indoor exposure periods. It is important to note that for many of the pollutants measured in the two field studies, there are no recommended health benchmarks or reference values.

Throughout this paper, we have referred to health benchmarks and reference values for comparing measured or calculated contaminant concentrations. For health benchmarks, it is important to distinguish which benchmarks are enforceable standards and which are recommendations or guideline values. For example, the National Institute for Occupational Safety and Health develops recommended exposure limits (RELs) for consideration by the Occupational Safety and Health Administration during the promulgation of legally enforceable permissible exposure limits (PELs) for occupational settings [31, 32]. NIOSH RELs are based on the best available science using human or animal health effects data. OSHA PELs, on the other hand, are subject to the public rulemaking process, and the interests of all affected parties scientific and otherwise - are taken into consideration. Therefore, caution must be taken when comparing health benchmarks for the same pollutant, as the rationale supporting an enforceable standard can be very different from that used to develop a guideline value.

Comparing health benchmarks across pollutants also poses a challenge. While one can compare two pollutants that share a common health endpoint, e.g., the potential to develop lung cancer, comparing the benchmarks of pollutants with different health endpoints assumes an equal level of acceptable risk among health benchmarks. For example, how does one compare the benchmarks of pollutants with carcinogenic health endpoints (e.g., an acceptable probability of 
getting cancer) with those of pollutants with non-cancer endpoints (e.g., an acceptable number of asthma attacks requiring hospitalization)?

Complicating things further, our bodies are exposed to pollutants in combination and such exposures can have synergistic impacts. For example, smokers exposed to radon are known to be at a sub-multiplicative risk of getting lung cancer, i.e., at greater risk than the combined risk calculated from exposures to the pollutants individually. Some contaminants, e.g., $\mathrm{CO}_{2}$, may not cause health effects at typical indoor concentrations, but are useful indicators for characterizing IAQ performance.

Lastly, it is important to emphasize that even comparisons of pollutant concentrations in buildings of the same type, and more so for different types, should be made with caution. Important differences include whether a building or owner- or tenant-occupied, the number of building occupants and their activities, and how the building was designed and is being operated. For example, ventilation system operation, which can be climate dependent, can have a dramatic effect on indoor pollutant concentrations. Pollutant concentrations of internally-generated contaminants are typically higher in a building operating at its minimum ventilation rate than one operating with $100 \%$ outside air, assuming the concentrations are lower in the outdoor air than in the building.

The preceding figures show how different pollutant parameters can be displayed to assess IAQ performance by comparing concentrations with respect to their health benchmarks. The determination of which parameters are considered can be case-specific depending on the objective of the analysis. That said, it would be helpful to arrive at an accepted collection of contaminants to allow comparisons among buildings and building datasets. For example, in commercial buildings, a user may wish to use the parameters included in the EPA BASE study 
[21], as it includes more pollutants than the SMCB study. For residential structures, the list of pollutants proposed by Logue et al. [33] may be useful. While the IAQ field is not at the point where an accepted list of indoor contaminants exists for either commercial or residential buildings, there have been useful discussions of what contaminants merit consideration [5, 34].

\section{Extending The Approach To Other Building Parameters}

This graphical approach can also be applied to a range of building performance considerations beyond IAQ. These include IEQ, energy and water consumption, the diversion of construction waste, and the handling of building waste generated during building use. IEQ includes consideration of thermal comfort, acoustics, and lighting. The application of the graphical approach to these additional attributes is relatively straightforward, as most of these parameters have more well-established health and/or comfort benchmarks or at least ranges of acceptability. For example, in the case of thermal comfort, one can use the metric of predicted percentage of dissatisfied occupants as defined in ASHRAE Standard 55, where $20 \%$ is considered an acceptable reference value [35]. For acoustics and lighting, as well as thermal comfort, there is a good discussion of reference values and measurement approaches in the Performance Measurement Protocols for Commercial Buildings recently published by ASHRAE [34, 36]. The PMP provide objectives, metrics, and benchmarks for each of these parameters at three levels of accuracy/cost: Basic, Intermediate, and Advanced.

Discussions of high performance buildings emphasize minimizing off-site sources of energy and water, as well as minimizing on-site waste generation. The graphical approach proposed here could also be used to represent these building parameters as well. For example, EUI, expressed 
in terms of energy per square area or energy per person, is a common benchmark used to compare the energy performance of buildings of similar function in the same climatic zone [37]. Data to do so in the United States can be found in the Commercial Building Energy Consumption Survey [38] and Residential Energy Consumption Survey [39]. In addition, energy performance can be simulated and compared to compliance with a given energy standard, e.g., ASHRAE Standard 90.1 or $90.2[40,41]$ or an energy rating system e.g., EPA's ENERGY STAR [42].

\section{CONCLUSIONS}

In this paper, we have reviewed previous attempts to characterize IAQ performance in buildings with metrics, noting the many challenges in doing so. To capture the robustness of indoor concentration data relative to available health benchmarks and other reference values, we have proposed a graphical approach to characterize IAQ performance. The approach was applied to selected studies of IAQ performance data to show its usefulness, particularly the facility with which one can: (a) identify an issue of potential concern, (b) compare the performance of multiple buildings and (c) evaluate the impact of design alternatives and intervention strategies in a given building. This graphical approach can be extended to consider additional building parameters, such as thermal comfort, lighting, and acoustics, as well as energy, water, and waste considerations.

\section{DISCLAIMER}

The views expressed in this paper are those of the authors and do not necessarily reflect those of the U.S. Environmental Protection Agency (EPA) and the National Institute of Standards and Technology (NIST). In addition, the full description of the procedures used in this paper requires 
the identification of certain commercial products and their suppliers. The inclusion of such information should in no way be construed as indicating that such products or suppliers are endorsed or recommended by EPA or NIST or that they are necessarily the best materials, instruments, software, or suppliers for the purposes described.

\section{REFERENCES}

[1] ASHRAE. ANSI/ASHRAE/USGBC/IES Standard 189.1-2011, Standard for the Design of High-Performance Green Buildings. American Society of Heating, Refrigerating and AirConditioning Engineers, Inc., Atlanta, GA; 2011.

[2] USGBC. LEED v4 for Building Design and Construction. U.S. Green Building Council; 2014.

[3] GBI. ANSI/GBI 01-2010 Green Building Assessment Protocol for Commercial Buildings. Green Building Initiative; 2010.

[4] ICC. 2012 International Green Construction Code. International Code Council, Inc.; 2012.

[5] Teichman KY, Persily AK, Emmerich SJ. Indoor Air Quality in High-Performing Building Case Studies: Got Data? HVAC\&R Research. 2014;Submitted for publication.

[6] Persily AK, Emmerich SJ. Indoor air quality in sustainable, energy efficient buildings. HVAC\&R Research. 2012;18:4-20.

[7] EPA. Program Needs for Indoor Environments Research (PNIER). U.S. Environmental Protection Agency; 2005.

[8] Deru M, Field K, Studer D, Benne K, Griffith B, Torcellini P, et al. U.S. Department of Energy Commercial Reference Building Models of the National Building Stock. Golden, CO: National Renewable Energy Laboratory; 2011.

[9] EPA. A Citizen's Guide To Radon. U.S. Environmental Protection Agency; 2012a.

[10] Satish U, Mendell MJ, Shekhar K, Hotchi T, Sullivan D, Streufert S, et al. Is CO2 an indoor pollutant? Direct effects of low-to-moderate CO2 concentrations on human decision-making performance. Environmental Health Perspectives. 2012;120:1671-7.

[11] Persily AK. Evaluating Building IAQ and Ventilation with Indoor Carbon Dioxide. ASHRAE Transactions. 1997;103 (2):193-204.

[12] Mølhave L. Volatile Organic Compounds, Indoor Air Quality and Health. Indoor Air. 1991;1 (4):357-76.

[13] ECA. Total Volatile Organic Compounds (TVOC) in Indoor Air Quality Investigations. Brussels: European Collaboration Action; 1997. 
[14] Weschler CJ, Shields HC. Indoor Ozone/Terpene Reactions as a Source of Indoor Particles. Atmospheric Environment. 1999;33:2307-18.

[15] Molhave L, Nielsen GD. Interpretation and Limitations of the Concept "Total Volatile Organic Compounds" (TVOC) as an Indicator of Human Responses to Exposures of Volatile Organic Compounds (VOC) in Indoor Air. Indoor Air. 1992;2 (2):65-77.

[16] ASHRAE. ANSI/ASHRAE Standard 62.1-2013 Ventilation for Acceptable Indoor Air Quality. American Society of Heating, Refrigerating and Air-Conditioning Engineers, Inc., Atlanta, GA.; 2013.

[17] ASHRAE. Indoor Air Quality Guide. Best Practices for Design, Construction, and Commissioning. Atlanta, GA: American Society of Heating, Refrigerating and Air-Conditioning Engineers; 2009.

[18] TenBrinke J, Selvin S, Hodgson AT, Fisk WJ, Mendell MJ, Koshland CP, et al. Development of New Volatile Organic Compound (VOC) Exposure Metrics and their Relationship to "Sick Building Syndrome" Symptoms. Indoor Air. 1998;8 (3):140-52.

[19] Sekhar SC, Tham KW, Cheong D, Kyaw TM, Susithra M. The Development of an Indoor Pollutant Standard Index. 8th International Conference on Indoor Air Quality and Climate. Edinburgh1999. p. 272-7.

[20] Hollick HH, Sangiovanni JJ. A Proposed Indoor Air Quality Metric for Estimation of the Combined Effects of Gaseous Contaminants on Human Health and Comfort. In: Nagda N.L., editor. Air Quality and Comfort in Airliner Cabins, ASTM STP 1393. West Conshohocken, PA: American Society for Testing and Materials; 2000. p. 76-98.

[21] Girman JR, Womble SE, Ronca EL. Developing Baseline Information on Buildings and Indoor Air Quality (BASE '94): Part II - Environmental Pollutant Measurements and Occupant Perceptions. Healthy Buildings '95. Milan1995. p. 1311-6.

[22] Moschandreas DJ, Sofuoglu SC. The Indoor Air Pollution Index. 8th International Conference on Indoor Air Quality and Climate. Edinburgh1999. p. 261-6.

[23] Mouradian L, Boulanger X. Qualite d'Air Interieur et Systems de Ventilation dans les Batiments a Basse Consummation d'Energie. Paris: L'Agence nationale de la recherche; 2012.

[24] Reif DM, Martin MT, Tan SW, Houck KA, Judson RS, Richard AM, et al. Endocrine profiling and prioritization of environmental chemicals using ToxCast data. Environmental Health Perspectives. 2010;118.

[25] ASHRAE. Guideline 10-2011 Interactions Affecting the Achievement of Acceptable Indoor Environments. American Society of Heating, Refrigerating and Air-Conditioning Engineers, Inc.; 2011.

[26] Ng LC, Musser A, Persily AK, Emmerich SJ. Indoor air quality analyses of commercial reference buildings. Building and Environment. 2012;58:179-87. 
[27] EPA. National Ambient Air Quality Standards. U.S. Environmental Protection Agency; 2012.

[28] Bennett D, Wu X, Trout A, Apte M, Faulkner D, Maddalena R, et al. Indoor Environmental Quality and Heating, Ventilating, and Air Conditioning Survey of Small and Medium Size Commercial Buildings. California Energy Commission; 2011.

[29] Emmerich S, Howard-Reed C. Modeling the IAQ Impact of HHI Interventions in Inner-City Housing. Indoor Air. 2005;15 (11):3495-9.

[30] OEHHA. Acute, 8-hour and Chronic Reference Exposure Levels. Office of Environmental Health Hazard Assessment, California Environmental Protection Agency. http://oehha.ca.gov/air/chronic rels/index.html.

[31] OSHA. Permissible Exposure Limits. Occupational Safety \& Health Adminisitration, U.S. Department of Labor; 2014.

[32] NIOSH. NIOSH Pocket Guide to Chemical Hazards. National Institute for Occupational Safety and Health; 2007.

[33] Logue JM, McKone TE, Sherman MH, Singer BC. Hazard assessment of chemical air contaminants measured in residences. Indoor Air. 2011;21:92-109.

[34] ASHRAE. Performance Measurement Protocols for Commercial Buildings. Atlanta GA: American Society of Heating, Refrigerating and Air-Conditioning Engineers, Inc.; 2010.

[35] ASHRAE. ANSI/ASHRAE Standard 55-2013, Thermal Environmental Conditions for Human Occupancy. American Society of Heating, Refrigerating, and Air-Conditioning Engineers, Inc., Atlanta, GA.; 2013a.

[36] Hunn BD, Haberl JS, Davies H, Owens B. Measuring Commercial Building Performance: Protocols for Energy, Water, and Indoor Environmental Quality. ASHRAE Journal. 2012;54(7).

[37] Peterson K, Crowther H. Building EUIs. High Performing Buildings. 2010:40-50.

[38] DOE. 2003 Commercial Building Energy Consumption Survey (CBECS). Energy Information Administration, U.S. Department of Energy. http://www.eia.doe.gov/emeu/cbecs/.

[39] DOE. 2009 Residential Energy Consumption Survey (RECS). Energy Information Administration, U.S. Department of Energy. http://www.eia.gov/consumption/residential/data/2009/.

[40] ASHRAE. ANSI/ASHRAE/IES Standard 90.1-2013 Energy Standard for Buildings Except Low-Rise Residental. American Society of Heating, Refrigerating and Air-Conditioning Engineers, Inc., Atlanta, GA.; 2013.

[41] ASHRAE. ANSI/ASHRAE Standard 90.2-2007 Energy-Efficient Design of Low-Rise Residential Buildings. American Society of Heating, Refrigerating and Air-Conditioning Engineers, Inc., Atlanta, GA.; 2007. 
[42] EPA. Energy Star. U.S. Environmental Protection Agency. http://www.energystar.gov.

Table 1 Summary of data from SMCB study illustrated in figure 2 (Bennett et al., 2011)

\section{Pollutant \\ Concentration \\ $\mathbf{u g} / \mathrm{m}^{3}$ \\ $\left(\mathrm{CO}_{2}\right.$ in $\left.\mathrm{mg} / \mathrm{m}^{3}\right)$}

13.8

817

33.09

1.53

53.69

0.75

4.07

1.63

6.47

0.3

30.83

19.22

$\begin{array}{cc}\text { Reference } & \begin{array}{c}\text { Calculated Sector } \\ \text { Value }\end{array} \\ \text { Radius }\end{array}$

35

1000

140

60

9

9

400

35

200

600

300

700
0.39

0.82

0.24

0.03

5.97

0.08

0.01

0.05

0.03

0.00

0.10

0.03

Notes:

1. Sector radii calculated to be between 0 and 0.25 are graphed as 0.25 to differentiate these sectors from those without measurements.

2. Sector radii calculated to be greater than 1.5 are graphed as 1.5 solely to minimize the graph size. 
Table 2 Summary of data from residential IAQ intervention study in figure 3 (Emmerich and Howard-Reed 2005)

$\begin{array}{lrrrrrr} & \begin{array}{c}\text { CO } \\ \mathbf{m g} / \mathbf{m}^{\mathbf{3}}\end{array} & \begin{array}{c}\text { CO } \\ \text { 1-hour } \\ \text { NAAQS }\end{array} & \begin{array}{c}\text { Calculated } \\ \text { Sector } \\ \text { Radius }\end{array} & \begin{array}{c}\text { NO2 } \\ \mathbf{m g} / \mathbf{m}^{3}\end{array} & \begin{array}{c}\text { NO2 } \\ \text { Annual } \\ \text { NAAQS }\end{array} & \begin{array}{c}\text { Calculated } \\ \text { Sector } \\ \text { Radius }\end{array} \\ \text { Baseline } & 45 & 43.2 & 1.04 & 0.26 & 0.107 & 2.43 \\ \text { Adjusted Stove } & 18 & 43.2 & 0.42 & 0.06 & 0.107 & 0.56 \\ \text { Kitchen Exh. Fan } & 31 & 43.2 & 0.72 & 0.15 & 0.107 & 1.40 \\ \text { Increased Mech. } & 39 & 43.2 & 0.90 & 0.23 & 0.107 & 2.15 \\ \text { Vent. } & 40 & 43.2 & 0.93 & 0.21 & 0.107 & 1.96 \\ \begin{array}{l}\text { Air Conditioner } \\ \text { House }\end{array} & 100 & 43.2 & 2.31 & 0.45 & 0.107 & 4.21 \\ \text { Tightening } & & & & & & \end{array}$

Notes:

1. Sector radii calculated to be between 0 and 0.25 are graphed as 0.25 to differentiate these sectors from those without measurements.

2. Sector radii calculated to be greater than 1.5 are graphed as 1.5 solely to minimize the graph size. 


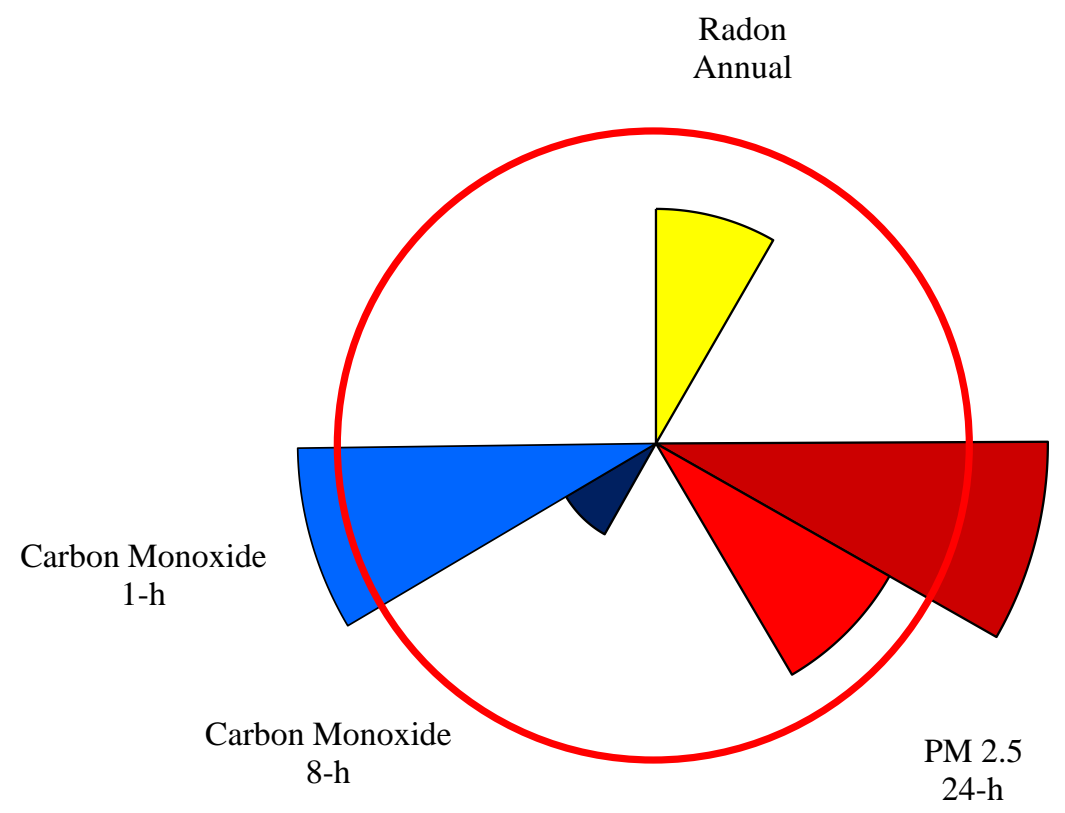

PM 2.5

Annual

Figure 1. Hypothetical Example of IAQ Graphic for Three Contaminants 


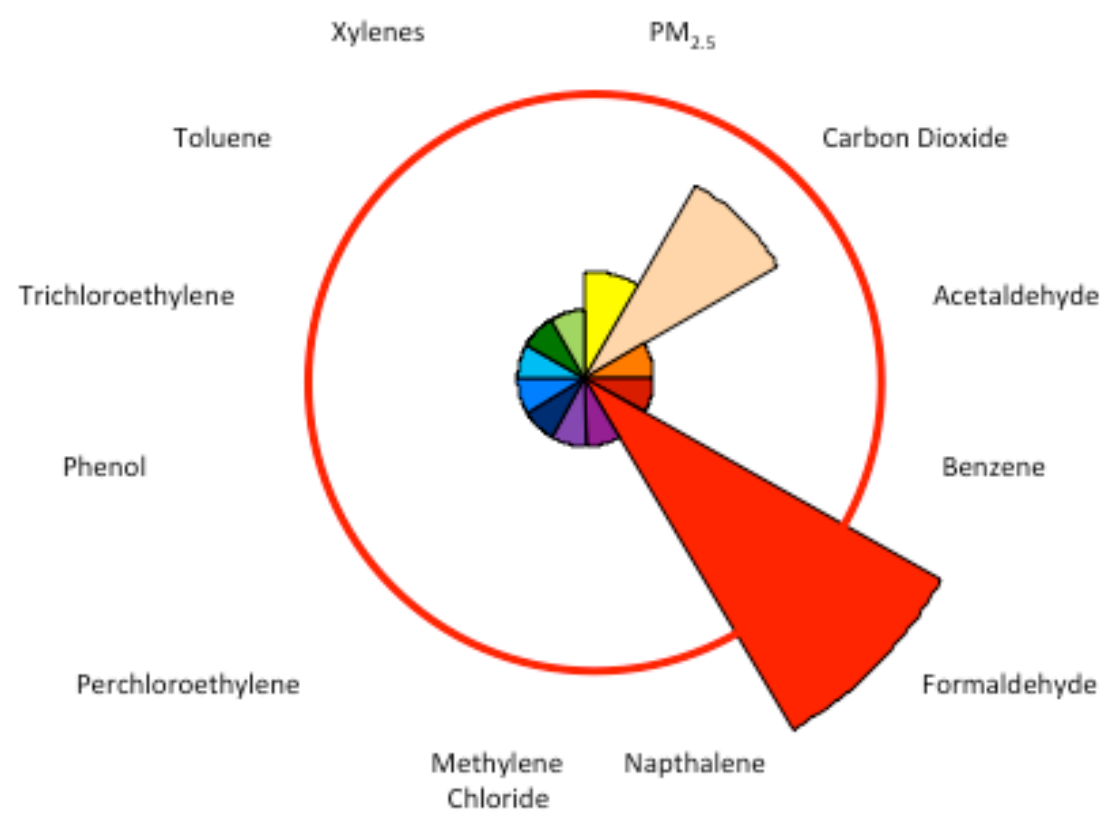

Figure 2. Data from Bennett et al. (2011) $\left(95^{\text {th }}\right.$ percentiles, except for PM2.5, which is at the 75 th percentile) vs. California Chronic Reference Exposure Level (except formaldehyde, which is for 8 hours) (OEHHA 2013) 


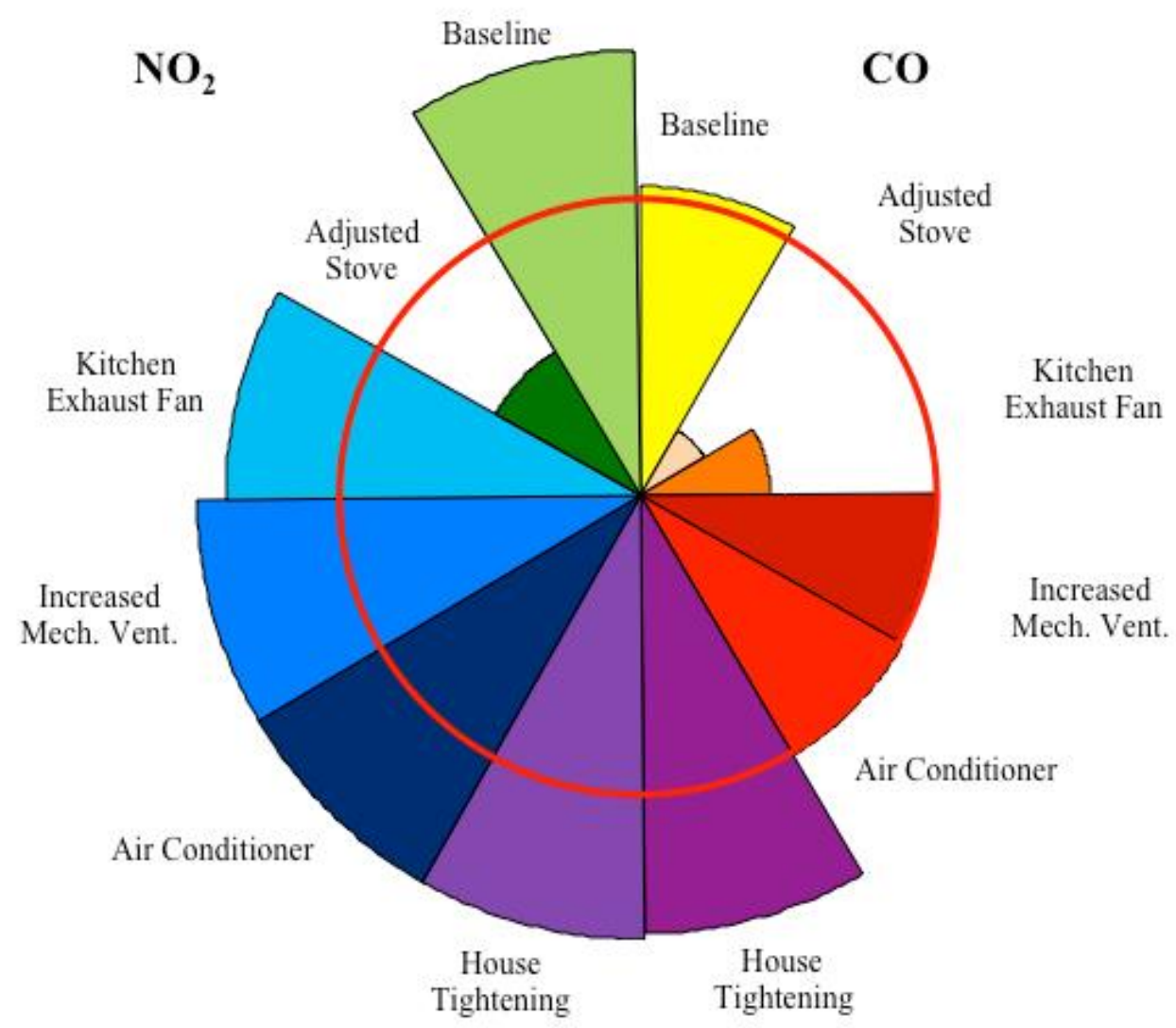

Figure 3. Data from Emmerich et al. (2005) simulating nitrogen dioxide and carbon monoxide concentrations in a summertime Boston kitchen with different gas stove interventions vs. the EPA one-hour NAAQS for CO and annual NAAQS for NO2 